\title{
Homerla Is Required for Establishment of Contralateral Bias and Maintenance of Ocular Dominance in Mouse Visual Cortex
}

\author{
ㅁarun Chokshi, ${ }^{1,2}$ Brian Druciak, ${ }^{1}$ Paul F. Worley, ${ }^{4}$ and ${ }^{\circledR}$ Hey-Kyoung Lee ${ }^{1,2,3,4}$ \\ ${ }^{1}$ The Zanvyl-Krieger Mind/Brain Institute, ${ }^{2}$ Cell Molecular Developmental Biology and Biophysics Graduate Program, ${ }^{3}$ The Kavli Neuroscience Discovery \\ Institute, Johns Hopkins University, Baltimore, Maryland 21218, and ${ }^{4}$ The Solomon H. Snyder Department of Neuroscience, Johns Hopkins School of \\ Medicine, Baltimore, Maryland 21205
}

It is well established across many species that neurons in the primary visual cortex (V1) display preference for visual input from one eye or the other, which is termed ocular dominance (OD). In rodents, V1 neurons exhibit a strong bias toward the contralateral eye. Molecular mechanisms of how OD is established and later maintained by plastic changes are largely unknown. Here we report a novel role of an activity-dependent immediate early gene Homerla (H1a) in these processes. Using both sexes of H1a knock-out (KO) mice, we found that there is basal reduction in the OD index of V1 neurons measured using intrinsic signal imaging. This was because of a reduction in the strength of inputs from the contralateral eye, which is normally dominant in mice. The abnormal basal OD index was not dependent on visual experience and is driven by postnatal expression of H1a. Despite this, H1a KOs still exhibited normal shifts in OD index following a short-term (2-3 d) monocular deprivation (MD) of the contralateral eye with lid suture. However, unlike wild-type counterparts, H1a KOs continued to shift OD index with a longer duration (5-6 d) of MD. The same phenotype was recapitulated in a mouse model that has reduced Homer 1 binding to metabotropic glutamate receptor 5 (mGluR5). Our results suggest a novel role of $\mathrm{H} 1 \mathrm{a}$ and its interaction with mGluR5 in strengthening contralateral eye inputs during postnatal development to establish normal contralateral bias in mouse V1 without much impact on OD shift with brief MD.

Key words: Homer1a; immediate early gene; monocular deprivation; ocular dominance; visual cortex

Significance Statement

Visual cortical neurons display varying degree of responsiveness to visual stimuli through each eye, which determines their ocular dominance (OD). Molecular mechanisms responsible for establishing normal OD are largely unknown. Development of OD has been shown to be largely independent of visual experience, but guided by molecular cues and spontaneous activity. We found that activity-dependent immediate early gene $\mathrm{Hla}$ is critical for establishing normal OD in V1 of mice, which show contralateral eye dominance. Despite the weaker contralateral bias, H1aKOs undergo largely normal OD plasticity. The basic phenotype of H1aKO was recapitulated by mGluR5 mutation that severely reduces H1a interaction. Our results suggest a novel role of mGluR5-H1a interaction in strengthening contralateral eye inputs to V1 during postnatal development.

\section{Introduction}

In higher mammals, most neurons in $\mathrm{V} 1$ respond to inputs from both eyes, but show varying degrees of preference toward one or

Received Dec. 11, 2018; revised March 5, 2019; accepted March 6, 2019.

Author contributions: V.C. and H.-K.L. designed research; V.C. and B.D. performed research; V.C. analyzed data; V.C. and H.-K.L. wrote the first draft of the paper; V.C.,P.F.W., and H.-K.L. edited the paper; V.C. and H.-K.L. wrote the paper; P.F.W. contributed unpublished reagents/analytic tools.

This work was supported by NIH Grant R01-EY014882 to H.-K.L. and R01-DA010309 to P.F.W.

The authors declare no competing financial interests.

Correspondence should be addressed to Hey-Kyoung Lee at heykyounglee@jhu.edu.

https://doi.org/10.1523/JNEUROSCI.3188-18.2019

Copyright $\odot 2019$ the authors the other eye. Although the initial setup of ocular dominance (OD) is known to depend largely on molecular cues and spontaneous activity (Rakic, 1976; Stryker and Harris, 1986; Horton and Hocking, 1996; Crowley and Katz, 2000; Espinosa and Stryker, 2012), alterations in visual experience during the early postnatal life can shift the OD of neurons. For instance, monocular deprivation during the critical period of development (3-5 weeks postnatally) induces a shift in OD toward the open eye. Studies have demonstrated that both Hebbian and homeostatic mechanisms underlie functional changes observed during various stages of OD plasticity (Espinosa and Stryker, 2012; Cooke and Bear, 2014). It is well established that OD plasticity occurs through two 
stages. Monocular deprivation (MD) first produces depression of the deprived eye response (2-3 d MD) through homosynaptic LTD mechanisms (Dudek and Bear, 1992; Kirkwood et al., 1993; Rittenhouse et al., 1999) followed by a delayed component (5-6 d $\mathrm{MD}$ ), which resembles homeostatic mechanisms, leading to strengthening of open-eye responses (Sawtell et al., 2003; Frenkel and Bear, 2004; Mrsic-Flogel et al., 2007; Ranson et al., 2012). There is strong evidence that weakening of the deprived eye response is because of NMDAR-dependent LTD (Rittenhouse et al., 1999; Heynen et al., 2003; Sawtell et al., 2003; Crozier et al., 2007), whereas there are a couple of alternatives proposed as the homeostatic plasticity mechanisms triggered during the later phase of OD plasticity (5-6 d MD). One mechanism proposed is synaptic scaling, which induces global cell-wide changes, hence can explain the parallel potentiation of both eye responses during the second phase of OD plasticity (Kaneko et al., 2008; Ranson et al., 2012). A second mechanism proposed is NMDAR-dependent metaplasticity, where loss of inputs coming from the deprived eye reduces the synaptic modification threshold to allow inputs from the open eye to potentiate following prolonged MD (Sawtell et al., 2003; Frenkel and Bear, 2004; Chen and Bear, 2007; Cho et al., 2009). The latter mechanism allows for input-specific changes and can explain potentiation of previously weaker inputs, as would happen when the dominant contralateral eye is sutured.

Homerla (H1a) is an immediate early gene expressed with increase in neuronal activity (Brakeman et al., 1997; Hu et al., 2010), and its expression is increased in V1 upon light exposure following a period of dark adaptation (Brakeman et al., 1997). Hence $\mathrm{Hla}$ is well posed to respond to changes in visual experience. In addition, $\mathrm{H} 1 \mathrm{a}$ is involved in homeostatic synaptic scaling observed in neuronal cultures upon chronic increase in activity (Hu et al., 2010) suggesting a role in homeostatic control of excitatory synaptic transmission. In this study, we aimed to study whether activity-dependent Hla expression is required for any of the processes mediating OD plasticity. Our initial hypothesis was that it would be involved in the homeostatic maintenance phase of OD with prolonged MD. Using optical imaging of intrinsic signals in V1, we report two novel mechanisms of H1a in OD plasticity: (1) H1a expression is required for the establishment of normal contralateral bias by strengthening contralateral eye inputs during postnatal development, which is independent of visual experience, and (2) Hla is not necessary for OD shift with short-term MD (2-3 d) but is involved in the later phase of OD plasticity (5-6 d MD).

\section{Materials and Methods}

Animals. Male and female mice were reared in a $12 \mathrm{~h}$ light/dark cycle. The knock-out for H1a (H1aKO), knock-in on the F1128R amino acid in the C-terminus of metabotropic glutamate receptor 5 (mGluR5; FRKI), and floxed-Homer1 (Homer $1^{\mathrm{fl} / \mathrm{fl}}$ ) line were obtained from Dr. Paul Worley (Johns Hopkins School of Medicine, Baltimore). Wild-type strains for $\mathrm{HlaKO}$ and FRKI were generated by breeding mutant mice with C57BL/6 (The Jackson Laboratory) mice, yielding H1aWT and FRWT, respectively. To create a conditional knock-out for Hla with the normal long form of Homer1, we created a H1aKOflox line $\left(\mathrm{H1b} / \mathrm{c}^{\mathrm{fl} /+} ; \mathrm{Hla}^{\mathrm{fl} /-}\right)$ by crossing Homer $1^{\mathrm{fl} / \mathrm{fl}}$ mice with HlaKO mice. HlaWTflox mice (H1b/ $\mathrm{c}^{\mathrm{f} /+} ; \mathrm{Hla}^{\mathrm{f} /++}$ ) were generated by breeding Homer $1^{\mathrm{f} / \mathrm{fl}}$ mice with HlaWT mice. All the animals were handled according to protocols approved by the Institutional Animal Care and Use Committee and guidelines provided by the Animal Care Act and National Institutes of Health.

Visual deprivation by dark rearing. Pregnant females and new born pups were dark reared (DR) in a dark room and were cared for with infrared vision goggles using dim infrared light. DR animals (see Fig. 3) were anesthetized in the dark room and brought to the imaging setup in a light tight box to minimize exposure to light.

MD by eye lid suture. Animals were monocularly deprived after each control imaging session by performing a monocular lid suture. During the procedure, animals were maintained at a deep anesthetic level using $1.5-2 \%$ isoflurane in oxygen (flow rate $1.0 \mathrm{~L} / \mathrm{min}$ ). Lid suturing was performed on the eye contralateral to the imaged V1. The upper and lower lids were slightly trimmed and then sutured together (Prolene P-6; Ethicon, catalog \#8648G). Animals recovered on a heating pad and then were returned to the animal colony. Each animal was housed individually until the next imaging session.

Bolus viral injection in new born pups. The home cage, containing pups and their mother, was brought to the injection setup. Pups (P0-P2) were anesthetized by placing them between a wet paper towel surrounded by ice for $5 \mathrm{~min}$ (Phifer and Terry, 1986). Under a dissection scope, V1 was located and viral injection was performed using an injection pump at 100 $\mathrm{nl} / \mathrm{s}$. The left hemisphere of each pup was injected with virus $(200 \mathrm{nl})$. Pups recovered at $37^{\circ} \mathrm{C}$ before being returned to their home cage. H1aKOflox or H1aWTflox (Worley laboratory, Johns Hopkins School of Medicine) were injected in V1 with either a Cre-expressing virus (AAV9.CaMKII.HI.eGFP-Cre.WPRE.SV40) to knock-out the floxed Homer1 hemi-gene or with a control enhanced GFP virus (AAV9. CaMKII0.4.eGFP.WPRE.rBG) to provide a control group.

Optical imaging of intrinsic signals. Mice were brought to the imaging setup in a fresh cage and anesthetized with 3\% isoflurane in $\mathrm{O}_{2}$ (flow rate: $1.0 \mathrm{~L} / \mathrm{min}$ ). The animals were head-fixed using a stereotaxic apparatus (Kopf Instruments) and maintained with constant level of isoflurane $(\sim 0.75 \%)$ in $\mathrm{O}_{2}$ (flow rate: $1.0 \mathrm{~L} / \mathrm{min}$ ) with single injection of chlorprothixene hydrochloride (Sigma-Aldrich, C1671; $2 \mathrm{mg} / \mathrm{kg}$ in saline). Heart rate was monitored and recorded during the imaging session using an EKG instrument (EKG, Harald Stauss Scientific). Temperature was maintained at $37^{\circ} \mathrm{C}$ with a heating pad. The imaging method developed in the Stryker laboratory (Kalatsky and Stryker, 2003; Cang et al., 2005) was used to measure the ocular dominance index in juvenile mice (P25$\mathrm{P} 35)$. A visual stimulus consisting of a horizontal bar moving in a vertical direction (upward and downward) was displayed in the binocular visual field $\left(-5^{\circ}-15^{\circ}\right.$ azimuth) to elicit responses in the binocular zone of V1. Vasculature was visualized by illuminating the surface of the brain with $555 \mathrm{~nm}$ light. Elicited responses were measured as changes in the reflectance of $610 \mathrm{~nm}$ light and were imaged transcranially with a Dalsa CCD camera through a coverslip fixed with $3 \%$ agarose. For each eye, cortical activity elicited at the stimulus frequency was calculated by Fourier analysis and presented as $\Delta R / R$ (reflectance of $610 \mathrm{~nm}$ light). The ocular dominance index was calculated as an average of (Contra-Ipsi)/ (Contra+Ipsi) from each pixel in a region-of-interest, which was manually selected on the basis of raw signal from ipsilateral eye responses with a threshold at $40 \%$ of the peak magnitude.

Confirmation of viral transfection by immunohistochemistry. Animals were deeply anesthetized with isoflurane after the final imaging session and were then transcardially perfused with $10 \mathrm{ml}$ of $0.1 \mathrm{M}$ PBS followed by $10 \mathrm{ml}$ of $10 \%$ formalin in $0.1 \mathrm{M}$ PBS. Brains were then harvested and fixed overnight in $10 \%$ formalin. V1 was isolated and $40 \mu \mathrm{m}$ thick slices were collected using a vibratome (Ted Pella). Free-floating sections were rinsed with PBS and permeabilized with 2\%Triton X-100 buffered in PBS solution. Following another wash, the slices were incubated in blocking buffer (10\% normal donkey serum, $0.2 \%$ Triton X-100, 4\% bovine serum albumin). Primary antibody treatment for NeuN (1:100 in blocking buffer; Millipore, catalog\# MAB377) was performed for $2 \mathrm{~d}$ at $4^{\circ} \mathrm{C}$. Afterward, slices were washed with PBS twice and treated with secondary antibody (Rabbit anti-mouse AlexaFluor 633; ThermoFisher Scientific). Slices were then washed, mounted on glass slides, and dried at room temperature for $20 \mathrm{~min}$. Coverslips were affixed using mounting media (Prolong gold antifade, Invitrogen) and sealed with nail polish. Slices were later imaged for NeuN (633) and Cre (GFP) expression with an LSM 510 confocal microscope.

Experimental design and statistical analysis. Experiments were designed to determine either changes associated with experimental manipulation (e.g., $\mathrm{MD}$ or DR) and/or genotype. All data are displayed as mean \pm standard error of mean (SEM). ANOVAs, two-way ANOVAs, and unpaired $t$ tests 

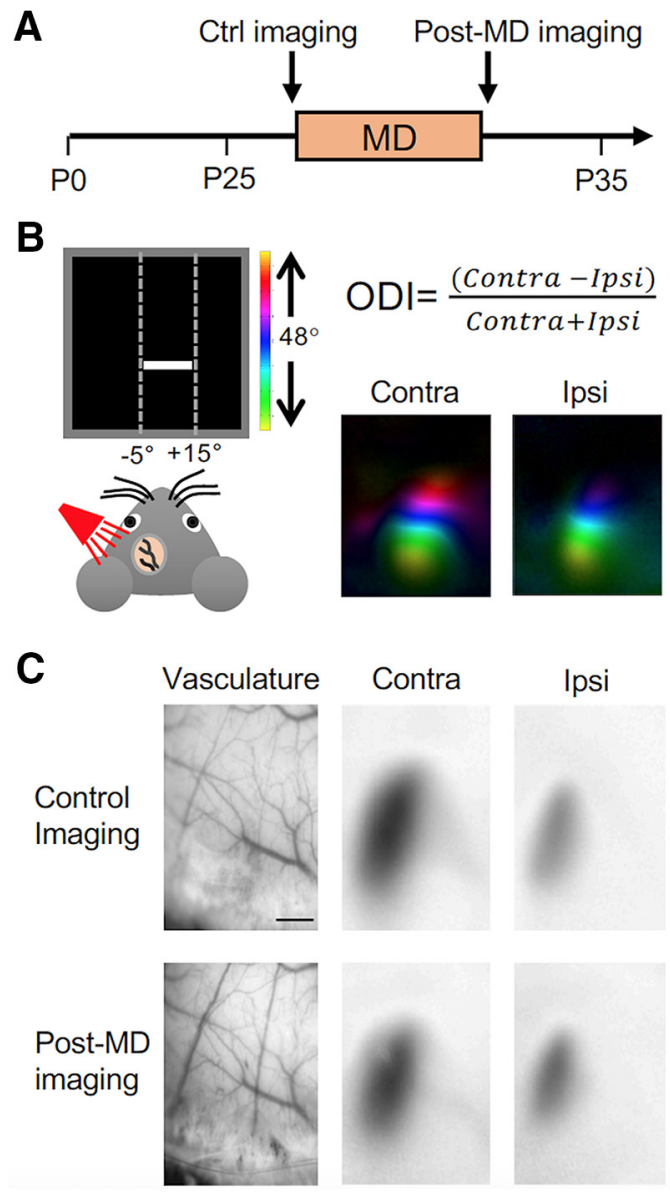

Figure 1. Experimental design and technique used for ODP measurement. $A$, Experimental paradigm for ODI measurement. Ctrl, Control. $\boldsymbol{B}$, Left, Schematic for imaging of intrinsic signals. Right, Top, 0DI calculation. Bottom, Example azimuth maps for stimulation in the binocular visual field. C, Example figure for repetitive imaging before and after MD. Scale bar, $1 \mathrm{~mm}$.

were performed using GraphPad Prism, as mentioned in each figure legend. Newman-Keuls multiple-comparison post hoc test was used following ANOVA to determine statistically significant difference between multiple groups as noted in each figure legend. Raw data are available on request.

\section{Results}

H1aKO exhibit abnormal contralateral bias and fails to maintain homeostatic OD plasticity

The role of H1a in OD plasticity was assessed by imaging of intrinsic signals produced in V1 by presentation of visual stimuli in the binocular visual field $\left(-5^{\circ}-15^{\circ}\right.$ azimuth) to each eye (Fig. 1 ). Visually evoked intrinsic signals were analyzed using previously reported method to calculate the ocular dominance index (ODI), which is basically a measure of response ratio between visual stimuli to the contralateral eye compared with that of the ipsilateral eye (Kalatsky and Stryker, 2003; Cang et al., 2005; see Materials and Methods; Fig. 1B). After a control imaging session, the contralateral eye was sutured for MD during the postnatal sensitive age for OD plasticity (P25-P35; Fig. 1A; Gordon and Stryker, 1996), and were reimaged either after 2-3 d MD or 5-6 d $\mathrm{MD}$ to assess changes to OD in V1. Vasculature imaging was done in parallel to confirm the imaging location (Fig. 1C).

In wild-type control, there was a basal contralateral bias in $\mathrm{V} 1$ indicating dominance of contralateral (contra) eye responses over ipsilateral (ipsi) eye (Fig. $2 A$ ), which was because of a greater response magnitude from the contralateral eye stimulation com-
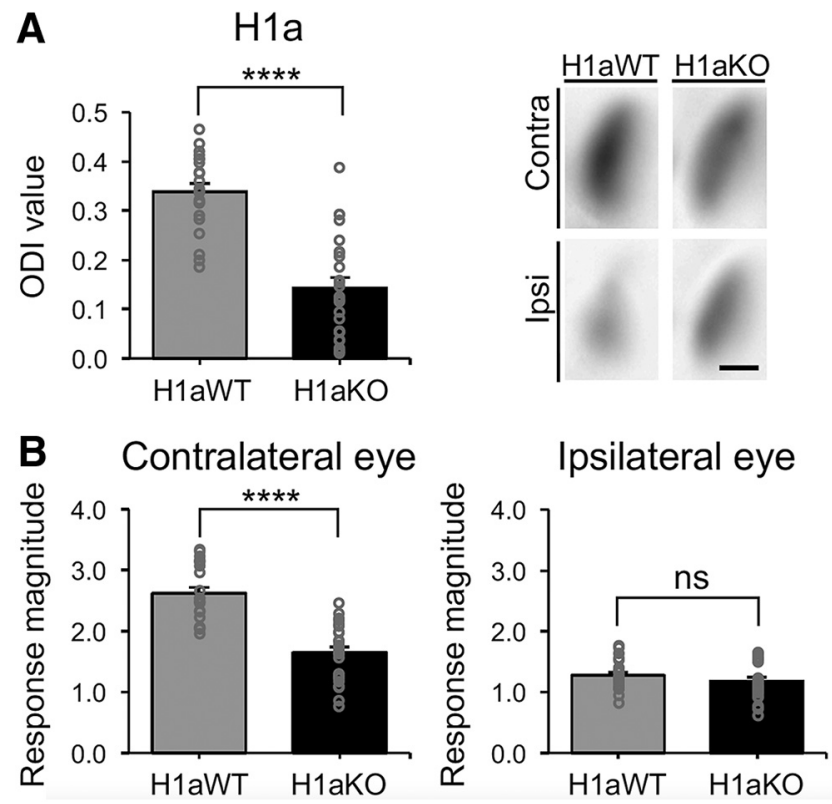

Figure 2. H1aK0 mice display reduced contralateral bias. Data shown as mean \pm SEM Response magnitude is of the order $\times 10^{-4}$. Statistics, Unpaired $t$ test. ${ }^{*} p<0.05,{ }^{* *} p<0.01$, ${ }^{* * *} p<0.001,{ }^{* * * *} p<0.0001$. $\boldsymbol{A}$, Left, Comparison of ODI measured from normal reared $\mathrm{H} 1 \mathrm{aWT}$ and H1aKO. Average ODI is shown as bars (mean $\pm \mathrm{SEM:ODI} \mathrm{of} \mathrm{H1aWT}=0.34 \pm 0.02$, ODI of H1aKO $=0.14 \pm 0.02$, unpaired $t$ test $p<0.0001, t=7.268, \mathrm{df}=45)$. ODI value from individual mice are plotted as gray circles. Number of animals, $n$ : H1aWT $=22, \mathrm{H} 1 \mathrm{aKO}=25$. Right, Example intrinsic signal images from H1aWT and H1aKO. Scale bar, $1 \mathrm{~mm}$. B, Comparison of response magnitude of intrinsic optical signals obtained by stimulating the contralateral eye (left) and ipsilateral eye (right) of normal reared mice. H1aKO showed a significantly lower contralateral eye responses compared with $\mathrm{H} 1 \mathrm{aWT}$ (Contra: $\mathrm{H} 1 \mathrm{aWT}=2.62 \pm 0.02 ; \mathrm{H} 1 \mathrm{aKO}=$ $1.65 \pm 0.09$; unpaired $t$ test $p<0.0001, t=7.123, \mathrm{df}=45$ ). There was no significant difference in ipsilateral eye responses between the two genotypes (Ipsi: H1aWT $=1.28 \pm$ 0.05 , H1aKO $=1.18 \pm 0.06$; unpaired $t$ test $p>0.25$; ns, not statistically significant, $t=$ $1.134, \mathrm{df}=45)$. Number of animals, $n$ : the same as in $\boldsymbol{A}$.

pared with that of the ipsi eye stimulation (Fig. 2B; response magnitude in the order of $10^{-4} \mathrm{H}$ laWT Ctrl: Contra $=2.62 \pm$ 0.10 , Ipsi $=1.28 \pm 0.05$, Student's paired $t$ test $p<10^{-13}$ ). Unexpectedly, H1aKO mice had significantly lower basal ODI than the wild-type controls (Fig. 2A). This decrease in contralateral bias in $\mathrm{HlaKO}$ mice was because of a reduction in the contra eye responses (Fig. 2B). The ipsi eye responses were comparable to that of H1aWT (Fig. $2 B$ ). These results suggest an unexpected novel role of $\mathrm{Hla}$ in strengthening the contralateral eye inputs to V1.

To determine whether H1a is involved in ocular dominance plasticity (ODP), we next performed varying durations of MD by suturing the contralateral eye (Fig. 3). In wild-type mice, 2-3 d MD significantly depressed deprived eye (contra) responses leading to a shift in ODI toward the open eye (ipsi; Fig. 3A). As reported earlier (Frenkel and Bear, 2004; Sato and Stryker, 2008; Ranson et al., 2012), this short duration MD (2-3 d MD) did not produce significant changes in the open-eye responses (Fig. $3 B$ ). However, a longer duration $\mathrm{MD}$ (5-6 d MD) led to strengthening of the open-eye (ipsi) responses along with a slight increase in deprived eye responses (Fig. $3 B)$. This led to a maintenance of ODI with longer MD to a similar level as that observed with shorter MD (Fig. 3A). Such maintenance of ODI with longer MD has been attributed to homeostatic plasticity mechanisms triggered by prolonged deprivation of visually-driven activity (Ranson et al., 2012).

Despite the reduced contralateral bias under normal conditions, upon 2-3 d MD H1aKO mice were able to produce normal 
depression of deprived-eye responses without affecting open-eye responses (Fig. 3D) resulting in a normal shift of ODI toward the open eye (Fig. 3C). However, ODI further shifted toward the open eye (ipsi) with 5-6 d MD (Fig. 3C). We observed normal open-eye potentiation during this phase of MD in H1a knockouts (KOs; Fig. 3D), which suggests that $\mathrm{Hla}$ is not involved in this process. Our results indicated that $\mathrm{H} 1 \mathrm{a}$ is not necessary for OD plasticity, but is required for the maintenance of ODI during longer periods of MD. In addition, we found a novel role of $\mathrm{H} 1 \mathrm{a}$ in setting up normal contralateral bias in rodent $\mathrm{V} 1$.

\section{$\mathrm{H1a}$ is necessary for postnatal} establishment of contralateral bias

Postnatal development of visual cortex involves refinement of connections that confers the cells with ocular selectivity. This phase occurs before eye opening in mice (Rakic, 1976; Li et al., 2008; Rochefort et al., 2011). However, visual experience after eye opening is necessary for maturation of individual eye responses in mammals including mice (Hubel and Wiesel, 1963; Wiesel and Hubel, 1974; Smith and Trachtenberg, 2007). Based on our observation of a lower basal ODI in $\mathrm{HlaKO}$, we examined whether this is because of lacking visual experiencedependent changes. To do this, we examined whether normal visual experience is needed to establish ODI in H1aWT and $\mathrm{H} 1 \mathrm{aKO}$ mice by dark rearing them from birth (Fig. 4A). ODI value in both $\mathrm{H}$ laWT and $\mathrm{H} 1 \mathrm{aKO}$ mice after dark rearing were comparable to their respective agematched normal reared groups (Fig. $4 B, D)$, suggesting that visual experience is not necessary to establish normal ODI values in either genotype. However, responses from individual eyes were significantly weaker as compared with normal reared animals in both genotypes (Fig. $4 C, E)$. Our results suggest that basal ODI measured in critical period mice is setup independent of visual experience. Based on this, we conclude that the lower basal ODI values seen in $\mathrm{H} 1 \mathrm{aKO}$ are not because of abnormal responses to visual experience during development but are because of a novel role of $\mathrm{Hla}$ in establishing contralateral eye input dominance in a visual experience-independent manner.

$\mathrm{HlaKO}$ is a constitutive $\mathrm{KO}$; hence we cannot rule out abnormalities in prenatal development that could have contributed to lower basal ODI. Prenatal development of visual cortex in mice involve genetic mechanisms that lay the chemo-
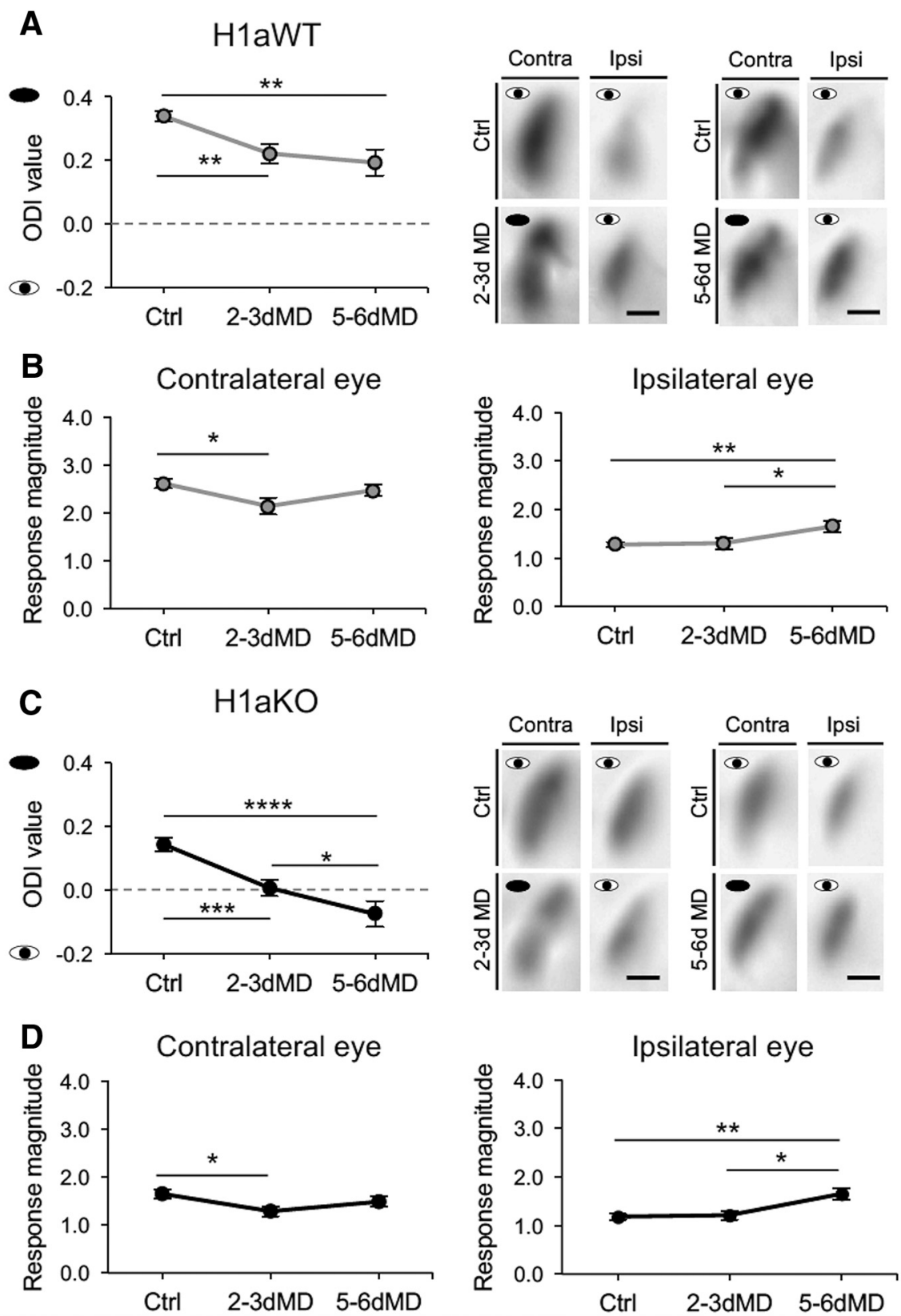

Figure 3. H1aKO mice show normal ODP with short-term MD, but fail to maintain ODI with longer-term MD. Data shown as mean \pm SEM. Response magnitude is of the order $\times 10^{-4}$. Statistics, ANOVA with Newman-Keuls multiple-comparison test. ${ }^{*} p<0.05,{ }^{* *} p<0.01,{ }^{* * *} p<0.001,{ }^{* * * *} p<0.0001$. A, Left, Average 0DI data measure in H1aWT with 2-3 d MD and 5-6d MD. ODI: $C$ trl $=0.34 \pm 0.02,2-3 \mathrm{~d} \mathrm{MD}=0.22 \pm 0.03 .5-6 \mathrm{~d} \mathrm{MD} \mathrm{ODI}=0.19 \pm 0.04$, ANOVA, $F_{(2,41)}=9.401, p=0.0004$; Newman-Keuls multiple-comparison test. Right, Example signals for each eye stimulation for corresponding MD and Ctrl groups. Scale Bar, $1 \mathrm{~mm}$. Number of animals, $n: C \operatorname{crl}=22,2-3 \mathrm{~d} M D=11,5-6 \mathrm{~d} M D=11$. $\boldsymbol{B}$, Contralateral and ipsilateral eye response magnitude measured in H1aWT mice during MD paradigms. Contra: $C$ trl $=2.62 \pm 0.10,2-3 \mathrm{~d} M D=2.14 \pm 0.17,5-6 \mathrm{~d} M D=$ $2.48 \pm 0.12$, ANOVA, $F_{(2,41)}=3.498, p=0.0396$; Newman-Keuls multiple-comparison test.; Ipsi: Ctrl $=1.28 \pm 0.05,2-3 \mathrm{~d}$ $M D=1.30 \pm 0.12,5-6 \mathrm{~d} M D=1.65 \pm 0.12$, ANOVA, $F_{(2,41)}=5.194, p=0.0098 ;$ Newman-Keuls multiple-comparison test. $n$, same as in $A$. C, Left, Average ODI data measure in H1aKO with 2-3 d MD and 5- $6 \mathrm{~d}$ MD. Right, Example signals for each eye stimulation for corresponding MD and Ctrl groups. ODI: $\mathrm{Ctrl}=0.14 \pm 0.02,2-3 \mathrm{~d} \mathrm{MD}=0.01 \pm 0.03,5-6 \mathrm{~d}$ MD $=-0.08 \pm$ 0.04, ANOVA, $F_{(2,47)}=18.200, p<0.0001$; Newman-Keuls multiple-comparison test. Right, Example signals for each eye stimulation for corresponding MD and Ctrl groups. Scale Bar, $1 \mathrm{~mm}$. Number of animals, $n: C \operatorname{trl}=25,2-3 \mathrm{dMD}=16,5-6 \mathrm{dMD}=$ 9. $D$, Contralateral and ipsilateral eye response magnitude in $\mathrm{H} 1 \mathrm{aKO}$ mice. Contra: $\mathrm{Ctrl}=1.65 \pm 0.09,2-3 \mathrm{~d} \mathrm{MD}=1.28 \pm 0.11$, $5-6 \mathrm{~d}$ MD $=1.49 \pm 0.10$, ANOVA, $F_{(2,47)}=3.479, p=0.0390$; Newman-Keuls multiple-comparison test. Ipsi: $C \operatorname{trl}=1.18 \pm$ $0.06,2-3 \mathrm{~d}$ MD $=1.21 \pm 0.09,5-6 \mathrm{~d}$ MD $=1.65 \pm 0.12$, ANOVA, $F_{(2,47)}=7.241, p=0.0018$; Newman-Keuls multiplecomparison test. $n$ : same as in $\boldsymbol{C}$. 
A

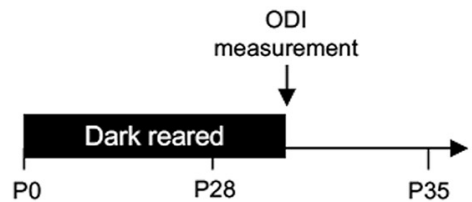

B

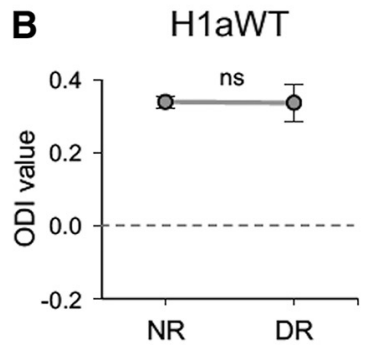

C Contralateral eye

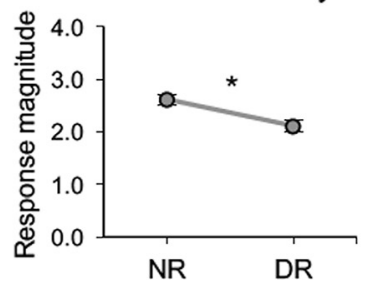

D H1aKO
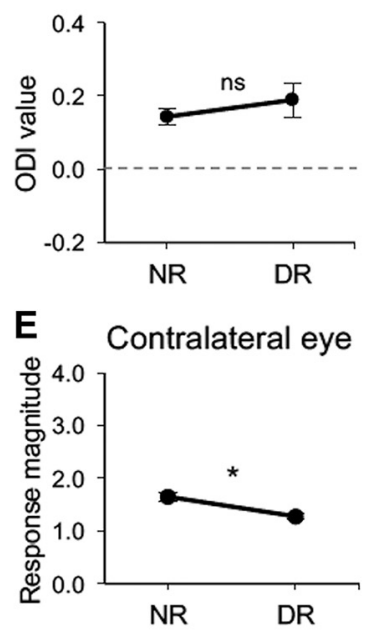
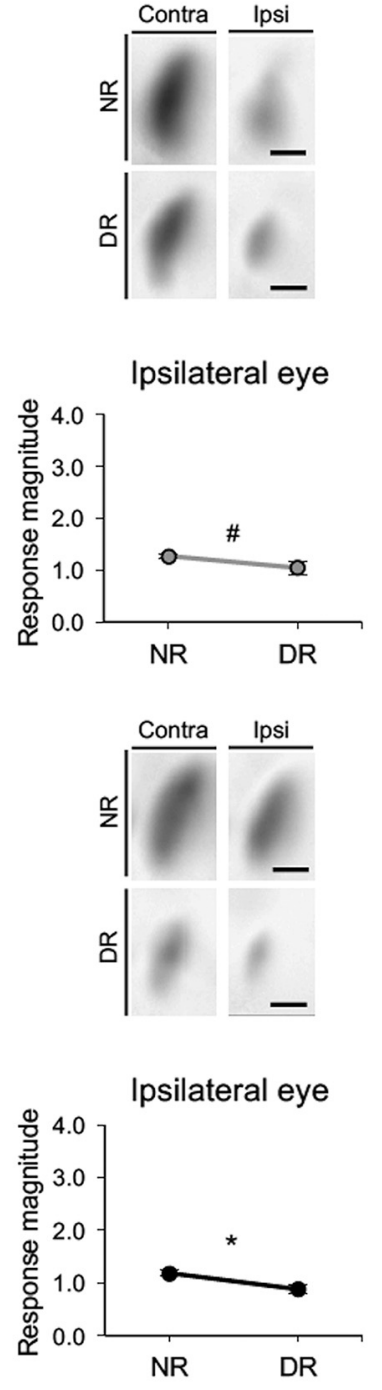

Figure 4. Developmental establishment of contralateral bias is not visual experiencedependent in both H1aWT and H1aKO. Data shown as mean \pm SEM. Response magnitude is of the order $\times 10^{-4}$. Statistics, Unpaired two-tailed Student's $t$ test. $\# p=0.06,{ }^{*} p<0.05$, ${ }^{* *} p<0.01,{ }^{* * *} p<0.001,{ }^{* * * *} p<0.0001$, \#p =0.06. A, Experimental design for measurement of $0 D$ in dark-reared animals. $\boldsymbol{B}$, Left, Average $0 \mathrm{DI}$ values measured in $\mathrm{H} 1 \mathrm{aWT}$, which were normal reared (NR) or DR from birth. H1aWT NR $=0.34 \pm 0.02, \mathrm{H} 1 \mathrm{aWT} D R=0.34 \pm 0.05$, unpaired $t$ test, $p=0.9430, t=0.0721, \mathrm{df}=27$. Right, Example intrinsic optical signals seen in V1 for each eye stimulation. Scale Bar, $1 \mathrm{~mm}$. Number of animals, $n$ : NR $=22 \mathrm{DR}=7$. C, Contralateral and ipsilateral raw response magnitude comparison between DR and NR in H1aWT mice. Contra: H1aWT NR $=2.62 \pm 0.10, \mathrm{H} 1 \mathrm{aWT} D \mathrm{DR}=2.12 \pm 0.12$, unpaired $t$ test, $p=0.0137, t=2.638, \mathrm{df}=27$; Ipsi: H1aWT NR $=1.28 \pm 0.05, \mathrm{H} 1 \mathrm{aWT}$ DR $=1.05 \pm 0.13$, unpaired $t$ test, $p=0.0614, t=1.952, \mathrm{df}=27$. Number of animals, $n$ : same as $\boldsymbol{A}$. $\boldsymbol{D}$, Left, Average ODI data measure in H1aKO in DR and NR mice. H1aKO NR $=0.14 \pm 0.02, \mathrm{H1aKODR}=$ $0.19 \pm 0.05$, unpaired $t$ test, $p=0.3262, t=0.9982, \mathrm{df}=30$. Right, Example signals for each eye stimulation. Scale bar, $1 \mathrm{~mm}$. Number of animals, $n$ : NR $=25 \mathrm{DR}=7$. $\boldsymbol{E}$, Contralateral and ipsilateral raw response magnitude comparison between DR and NR in Contra: H1aKO NR = $1.65 \pm 0.10, \mathrm{H} 1 \mathrm{a} \mathrm{KO} \mathrm{DR}=1.27 \pm 0.06$, unpaired $t$ test $p=0.0469, t=2.072, \mathrm{df}=30$; Ipsi: H1aKO NR $=1.18 \pm 0.06, \mathrm{H} 1 \mathrm{aKO} D \mathrm{DR}=0.88 \pm 0.08$, unpaired $t$ test $p=0.0199, t=2.460$, $\mathrm{df}=30$. Number of animals, $n$ : same as $\boldsymbol{D}$. architecture to drive correct connections from the eye through thalamus (O'Leary et al., 2007; Kanold and Luhmann, 2010). To determine whether $\mathrm{H1a} \mathrm{KO}$ during this phase of development was affecting the establishment of ODI, a conditional $\mathrm{KO}$ was required. However, H1a is a splice variant of a constitutive form of Homer1 (Homer1b/c; H1b/c) and exists on the same gene. Hence generation of Cre-inducible conditional Hla KO mice (H1aKOflox, H1b/ $\mathrm{c}^{\mathrm{fl} /+} ; \mathrm{H} 1 \mathrm{a}^{\mathrm{f} /--}$ ) was performed by crossbreeding floxed-Homerl mice $\left(\mathrm{H} 1 \mathrm{~b} / \mathrm{c}^{\mathrm{fl} / \mathrm{fl}} ; \mathrm{H}^{\mathrm{f}} \mathrm{a}^{\mathrm{fl} / \mathrm{l}}\right)$ with $\mathrm{H} 1 \mathrm{aKO}$ mice (Fig. 5B). This allows temporal control for KO of Homer1 variants postnatally. Cre was expressed postnatally by injection of CaMKII promoter driven Cre adeno-associated virus system (AAV9.CaMKII.Cre.GFP) in new born pups (P0-P1; Fig. 5A). This method produced widespread expression of Cre in the postnatal brain as visualized by the GFP tag (Fig. $5 C, D$ ). In this system, Cre-expressing neurons are conditional KOs of $\mathrm{Hla}(\mathrm{Hlb} /$ $\left.\mathrm{c}^{+/-} ; \mathrm{Hla}^{-l-}\right)$. To control for viral injections, control mice were injected with only GFP-expressing virus (AAV9.CaMKII.eGFP) driven by CaMKII promoter to generate $\mathrm{H1b} / \mathrm{c}^{+/+} ; \mathrm{Hla}^{+/-}$neurons. Under this scheme, Cre injected conditional $\mathrm{KO}$ of $\mathrm{Hla}$ is also heterozygous for $\mathrm{H} 1 \mathrm{~b} / \mathrm{c}\left(\mathrm{H} 1 \mathrm{~b} / \mathrm{c}^{+/-} ; \mathrm{Hla}^{-1-}\right)$, but the GFP only group is wild-type for $\mathrm{H} 1 \mathrm{~b} / \mathrm{c}$ but heterozygous of $\mathrm{Hla}(\mathrm{H} 1 \mathrm{~b} /$ $\left.\mathrm{c}^{+/+} ; \mathrm{Hla}^{+/-}\right)$. Therefore, to control for the differences in $\mathrm{Hlb} / \mathrm{c}$ and Hla gene dosage, we also generated a set of control animals by cross-breeding floxed-Homer1 mice $\left(\mathrm{H} 1 \mathrm{~b} / \mathrm{c}^{\mathrm{f} / \mathrm{fl}} ; \mathrm{H} 1 \mathrm{a}^{\mathrm{f} / \mathrm{fl}}\right)$ with $\mathrm{H} 1 \mathrm{aWT}$, which produced $\mathrm{H} 1 \mathrm{aWT}$ flox mice $\left(\mathrm{H1b} / \mathrm{c}^{\mathrm{fl} /+} ; \mathrm{Hla}^{\mathrm{fl} /+}\right)$. Without any viral injections these mice are wild-type for both $\mathrm{H} 1 \mathrm{~b} / \mathrm{c}$ and $\mathrm{Hla}\left(\mathrm{H} 1 \mathrm{~b} / \mathrm{c}^{+/+} ; \mathrm{Hla}^{+/+}\right)$, and with Cre-GFP injection they produce neurons which are heterozygous for both $\mathrm{H} 1 \mathrm{~b} / \mathrm{c}$ and $\mathrm{Hla}\left(\mathrm{H} 1 \mathrm{~b} / \mathrm{c}^{+/-} ; \mathrm{Hla}^{+/-}\right)$. As summarized in Figure 6, by comparing the four groups $\left(\mathrm{H1b} / \mathrm{c}^{+/+} ; \mathrm{Hla}^{+/+}, \mathrm{H1b} / \mathrm{c}^{+/+}\right.$; $\mathrm{Hla}^{+/-}, \mathrm{H1b} / \mathrm{c}^{+/-} ; \mathrm{Hla}^{+/-}$, and $\left.\mathrm{H} 1 \mathrm{~b} / \mathrm{c}^{+/-} ; \mathrm{Hla}^{-1-}\right)$ we were able to compare dose-dependent effects of $\mathrm{H} 1 \mathrm{~b} / \mathrm{c}$ and $\mathrm{H} 1 \mathrm{a}$ expression. ODI measurement was done during the critical period of OD plasticity (P28-P35; Fig. 6). All the animals were confirmed for expression of virus after the imaging session (Fig. $5 C, D)$. The transfection efficiency in groups receiving Cre-GFP virus $\left(\mathrm{H1b} / \mathrm{c}^{+/-} ; \mathrm{Hla}^{+/-}\right.$and $\mathrm{H} 1 \mathrm{~b} / \mathrm{c}^{+/-} ; \mathrm{Hla}^{-1-}$ ) was $\sim 90 \%$.

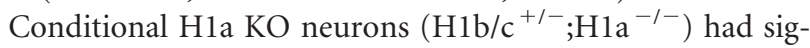
nificantly lower contralateral bias than the Homer1 wild-type group $\left(\mathrm{H1b} / \mathrm{c}^{+/+} ; \mathrm{Hla}^{+/+} ;\right.$Fig. $\left.6 A\right)$. However, heterozygous H1a controls $\left(\mathrm{H1b} / \mathrm{c}^{+/+} ; \mathrm{Hla}^{+/-}\right.$and $\left.\mathrm{H1b} / \mathrm{c}^{+/-} ; \mathrm{Hla}^{+/-}\right)$were not significantly different from either of the groups, which suggests that there might be $\mathrm{Hla}$ gene dose-dependent regulation of ODI during postnatal development. Although there was a trend of a decrease in contralateral eye responses and a slight increase in ipsilateral eye responses in the $\mathrm{H} 1 \mathrm{~b} / \mathrm{c}^{+/-} ; \mathrm{H}^{\mathrm{a}} \mathrm{a}^{-1-}$ group, this did not reach statistical significance when compared with other groups (Fig. 6B). These observations support the premise that H1a expression during postnatal development is required to establish normal contralateral bias in V1.

Homer1 interaction with mGluR5 is required for establishing contralateral bias and OD maintenance

H1a acts by displacing long-forms of Homerl from their binding partners, one of which is mGluR5. To determine whether the function of $\mathrm{Hla}$ in establishing basal ODI and maintaining OD shift is because of its interaction with mGluR5, OD plasticity was assessed in transgenic mice with mutations on mGluR5 that severely reduces Homer1 binding (F1128R mutation; FRKI; Park et al., 2013). Similar to HlaKOs, FRKI mice had significantly lower contralateral bias than FRWT mice under basal control conditions (Fig. $7 A, C$; ODI, FRWT: $\mathrm{Ctrl}=0.32 \pm 0.03$, FRKI: $\mathrm{Ctrl}=$ 
$0.21 \pm 0.03$, unpaired $t$ test $p<0.05)$. Furthermore, long-term MD (5-6 d MD) produced significantly greater decrease in ODI than the wild-type animals similar to what we observed in $\mathrm{HlaKO}$ (two-way ANOVA for ODI between FRWT versus FRKI shows statistically significant interaction: ${ }^{\star} p=0.0471, F_{(1,12)}=4.892$; Fig. $7)$. Our results suggest that mGluR5 interaction with Homer1 is required for establishing basal ODI and for maintenance of OD during longer durations of MD (5-6 d MD). Although we cannot exclude the possibility that FRKI phenotype is because of reduced binding of mGluR5 to long forms of Homer1, our observation that FRKI phenocopies $\mathrm{H} 1 \mathrm{aKO}$ can be explained most parsimoniously by the loss of mGluR5-H1a interaction. Furthermore, long forms of Homer1 are expressed in greater abundance compared with its splice variant H1a, hence reduced affinity of mGluR5 to these two splice variants is expected to more severely affect the formation of mGluR5-H1a complexes.

\section{Discussion}

The main finding of this study is that $\mathrm{Hla}$ and its interaction with mGluR5 are required for establishing the normal contralateral bias in V1 and maintenance of OD following longer periods of MD. Even with the lower basal ODI, H1aKO displayed OD shifts with short-term MD, which suggests that the initial phase of $\mathrm{MD}$, which is mainly driven by weakening of the closed-eye inputs, is not dependent on H1a expression. Moreover, we found evidence that H1a and mGluR5 interaction is critical for establishing the basal ODI and for preventing a further decrease in ODI during longer-term MD.

H1a is not necessary for OD plasticity with short-term MD, but needed for preventing a further shift in ODI with long-term MD

Short-term MD (2-3 d MD) predominantly drives weakening of the closedeye inputs via NMDAR-dependent LTD mechanisms (Rittenhouse et al., 1999; Heynen et al., 2003; Sawtell et al., 2003; Crozier et al., 2007). Longer duration MD (5-6 d MD) has a delayed additional component that is thought to be produce by homeostatic plasticity that involves potentiation of open-eye inputs (Sawtell et al., 2003; Frenkel and Bear, 2004; Chen and Bear, 2007; Kaneko et al., 2008; Cho et al., 2009; Ranson et al., 2012). Recently it was reported that global synaptic scaling mechanisms through glial-derived tumor necrosis factor (TNF $\alpha$; Kaneko et al.,

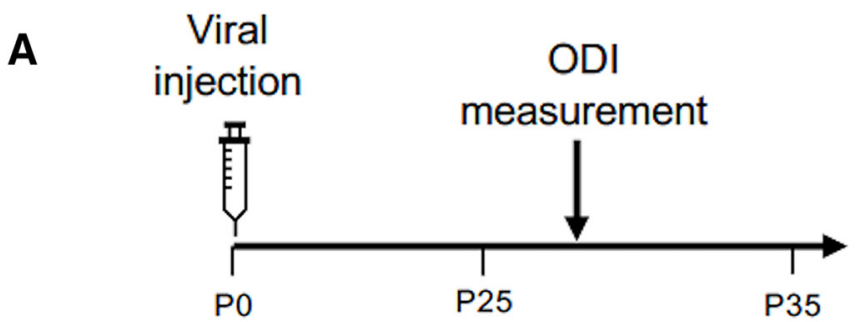

B
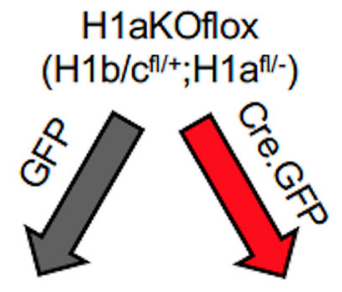

H1aWTflox

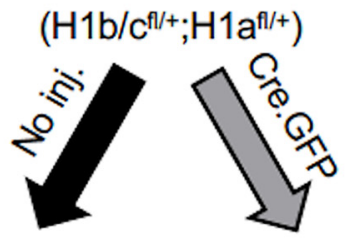

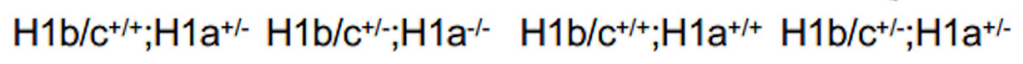
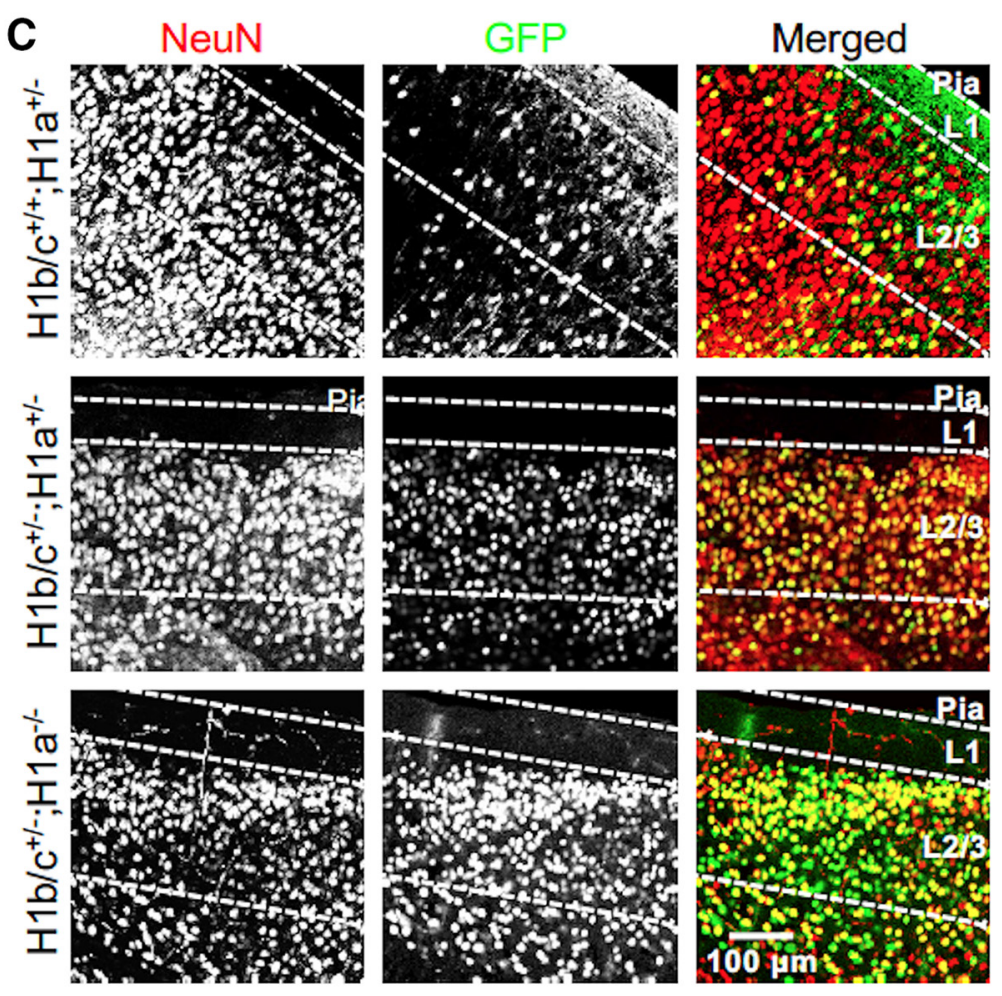

D

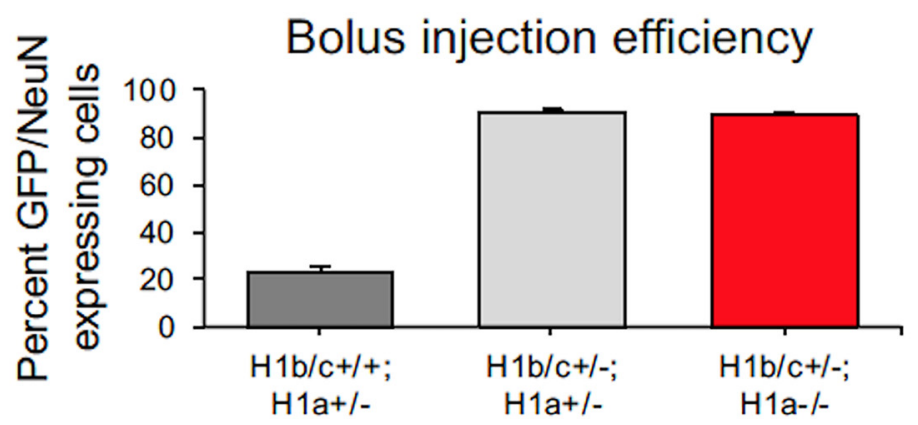

Figure 5. Generation of $\mathrm{H} 1 \mathrm{a}$ conditional $\mathrm{KO}$ neurons in V1. $\boldsymbol{A}$, Experimental design for bolus injection of AAV virus at birth and ODI measurement during critical age for ODP. B, Genetic design to produce H1a conditional KO neurons in cortex. Inj, Injection. For virus information see methods. C, Example slices showing transfection levels of virus in $\mathrm{V} 1 \mathrm{~L} 2 / 3$ in all the three conditions. NeuN (red), Neuronal marker; GFP (green), marker for viral infection. D, Quantification for viral transfection efficiency as percentage of GFP-expressing cells per NeuN-expressing neurons. 


\section{A Postnatal knockdown of $\mathrm{H} 1 \mathrm{a}$}
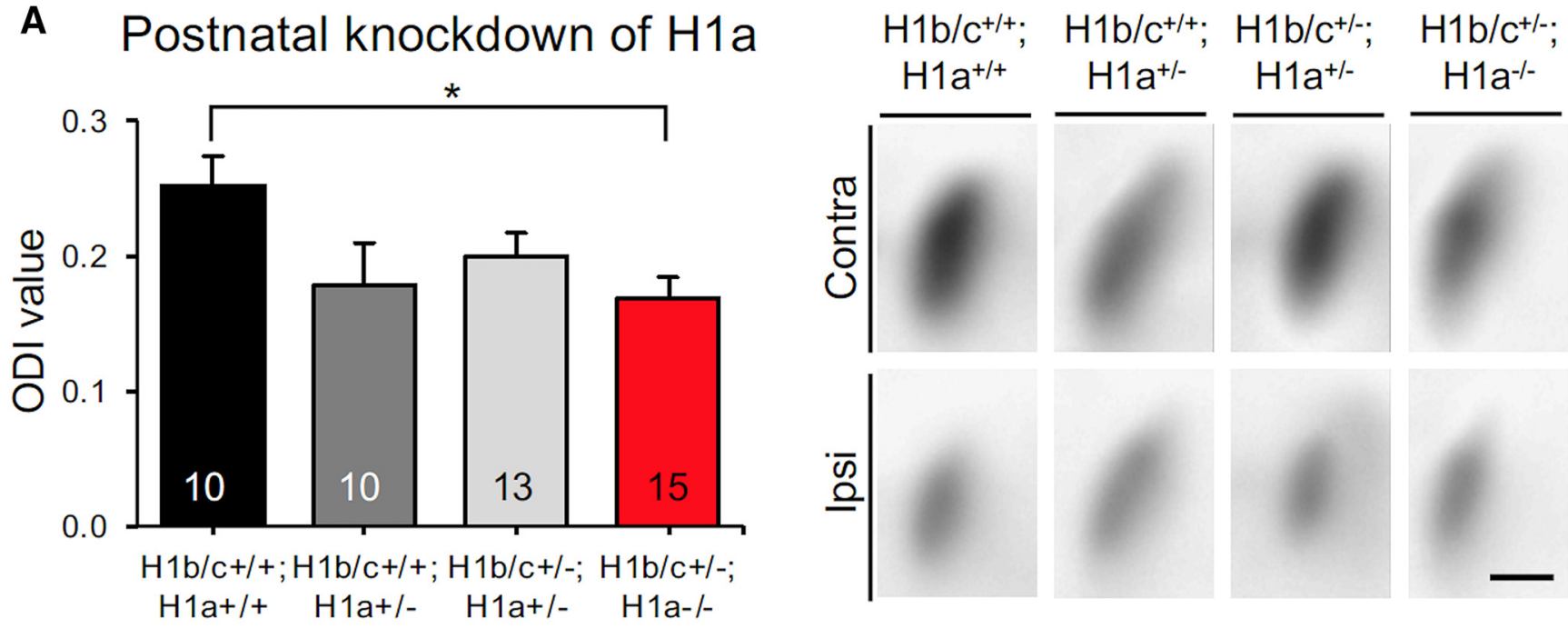

B Contralateral eye
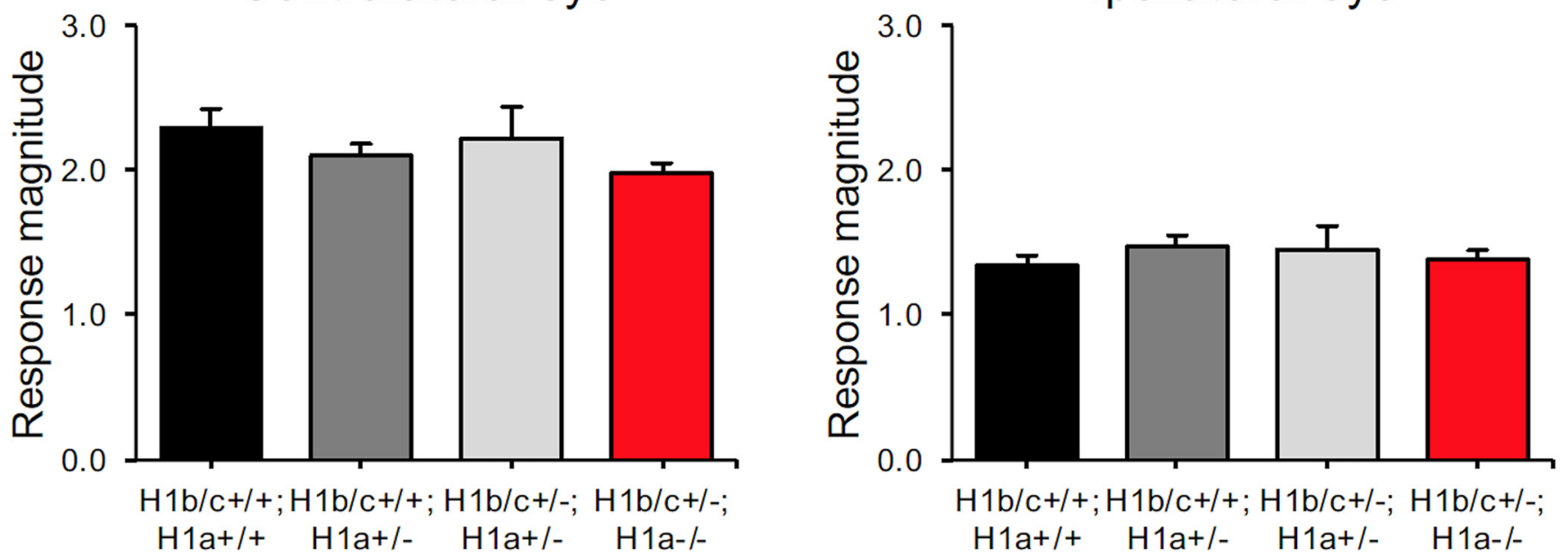

Figure 6. Postnatal H1a expression is required for establishing normal contralateral bias. Data shown as mean \pm SEM. Response magnitude is of the order $\times 10^{-4}$. Number of animals, $n$, is noted on the bar of each group. Statistics, ANOVA with Newman-Keuls multiple-comparison test. ${ }^{*} p<0.05,{ }^{* *} p<0.01,{ }^{* * *} p<0.001$, ${ }^{* * * *} p<0.0001$. A, Left, Average basal 0DI data measured

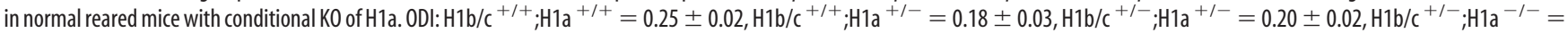
$0.17 \pm 0.02$, ANOVA, $F_{(3,44)}=3.084, p<0.0369$; Newman-Keuls multiple-comparison test. Right, Example intrinsic optical signals for each eye stimulation. Scale bar, 1 mm. Number of animals noted at the base of the bar for each condition. $B$, Contralateral and ipsilateral eye response magnitude for each condition. Contra: $\mathrm{H1b} / \mathrm{C}^{+/+} ; \mathrm{H1a}{ }^{+/+}=2.29 \pm 0.13, \mathrm{H} 1 \mathrm{~b} / \mathrm{c}^{+/+} ; \mathrm{H} 1 \mathrm{a}{ }^{+/-}=$ $2.10 \pm 0.08, \mathrm{H1b} / \mathrm{c}^{+/-} ; \mathrm{H} 1 \mathrm{a}^{+/-}=2.22 \pm 0.22, \mathrm{H1b} / \mathrm{c}^{+/-} ; \mathrm{H1a}{ }^{-/-}=1.98 \pm 0.07$, ANOVA, $F_{(3,44)}=0.966, p=0.4173 ;$ Newman-Keuls multiple-comparison test; Ipsi: H1b/c ${ }^{+/+}$;

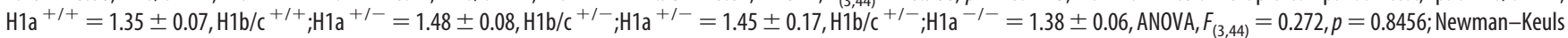
multiple-comparison test. Number of animals, $n$ : same as $\boldsymbol{A}$.

2008) are required for this later phase of ODP. TNF $\alpha$ has been shown to be specifically involved in homeostatic plasticity and is not necessary for Hebbian forms of plasticity (Beattie et al., 2002; Kaneko et al., 2008; Steinmetz and Turrigiano, 2010; Pribiag and Stellwagen, 2014). Kaneko et al. (2008) observed blockade of open-eye potentiation in TNF $\alpha \mathrm{KO}$ mice. However, their contralateral bias was maintained during the later phase of MD.

We found that H1a KOs, despite having basally low contralateral bias, undergo normal OD shift to favor the open-eye inputs with short-term MD (2-3 d), which was mediated by depression of the deprived contralateral eye inputs (Fig. 3). This suggests that $\mathrm{H} 1 \mathrm{a}$ is not critical for mediating this process, and that the lower contralateral eye responses under basal conditions does not preclude further weakening. This finding is consistent with the idea that activity-dependent synaptic weakening process does not require $\mathrm{Hla}$, and supports the idea that NMDA receptordependent LTD-like processes are involved (Rittenhouse et al.,
1999; Heynen et al., 2003). However, we found that H1a KOs display a further reduction in ODI upon longer duration of MD (5-6 d; Fig. 3). In wild-types, ODI does not shift further because of a delayed potentiation of both the deprived eye and the openeye inputs (Fig. 3). The delayed open-eye potentiation was still intact in $\mathrm{Hla}$ KOs suggesting that $\mathrm{Hla}$ is not involved in this process. The larger reduction in ODI seen with longer-term MD (5-6 d) was recapitulated in mGluR5 knock-in mice that have severely reduced affinity to Homer1 (FRKI; Fig. 7). This suggests that $\mathrm{H} 1 \mathrm{a}$ interaction with mGluR5 plays a role in preventing a further decline in ODI during the later phase of MD.

\section{Development of OD}

Development of OD of V1 neurons happens before eye opening in mice and kittens. Establishment of OD is dependent on retinal spontaneous activity rather than visual experience (Hubel and Wiesel, 1963; Stryker and Harris, 1986; Crair et al., 1998). Block- 
ade of spontaneous retinal activity after eye opening prevents the normal developmental pruning of thalamocortical arbors in V1 layer 4 (Antonini and Stryker, 1993). In addition, correlated spontaneous activity in the visual thalamus (LGNd) is sufficient to produce ocular dominance columns in ferret V1 (Weliky and Katz, 1999; Chiu and Weliky, 2001). Consistent with these studies, we found that normal contralateral bias is established even when mice are dark reared from birth with no visual experience (Fig. 4B). However, molecular mechanisms underlying the normal establishment of OD are not well understood. We found that establishment of contralateral bias is severely impacted in $\mathrm{H} 1 \mathrm{aKO}$ mice, which persisted even when $\mathrm{H} 1 \mathrm{aKO}$ are raised in the dark from birth (Fig. 4D). This was because of abnormally weak contralateral responses in V1. Ipsilateral eye responses were similar to what is observed in WTs. Furthermore, we demonstrated that postnatal expression of Hla is important for this contralateral bias, because inducing conditional $\mathrm{KO}$ of $\mathrm{H}$ la postnatally recapitulated the lower ODI (Fig. 6A). This suggests that spontaneous activity in the absence of vision, such as retinal waves or spontaneous LGN and/or cortical activity, may be sufficient to trigger $\mathrm{Hla}$ activation to support the development of contralateral bias in V1. The exact mechanism in which $\mathrm{H} 1$ a regulates the strength of contralateral eye inputs will require further studies, but we demonstrated that its interaction with mGluR5 is critical for this process using mice carrying mutations on the mGluR5 that lack H1a binding (FRKI; Fig. 7). Although the role of $\mathrm{Hla}$ in homeostatic scaling down of synaptic strength has been shown in neuronal cultures (Hu et al., 2010), its role in strengthening inputs has not been reported. Furthermore, our results would suggest that $\mathrm{Hla}$ rather selectively works on contralateral eye inputs to establish the normal contralateral bias. The exact mechanism as to how Hla can achieve input-specific control of contralateral eye inputs would require further investigation. On the surface, our results differ from a proposed role of $\mathrm{Hla}$ in global homeostatic downregulation of synaptic strength as reported in cultured neurons (Hu et al., 2010), which may be because of differences in preparation. One potential explanation that could reconcile this apparent contradiction is that mGluR5-H1a interaction enables plasticity, but does not determine the polarity of synaptic plasticity, and whether it results in global or
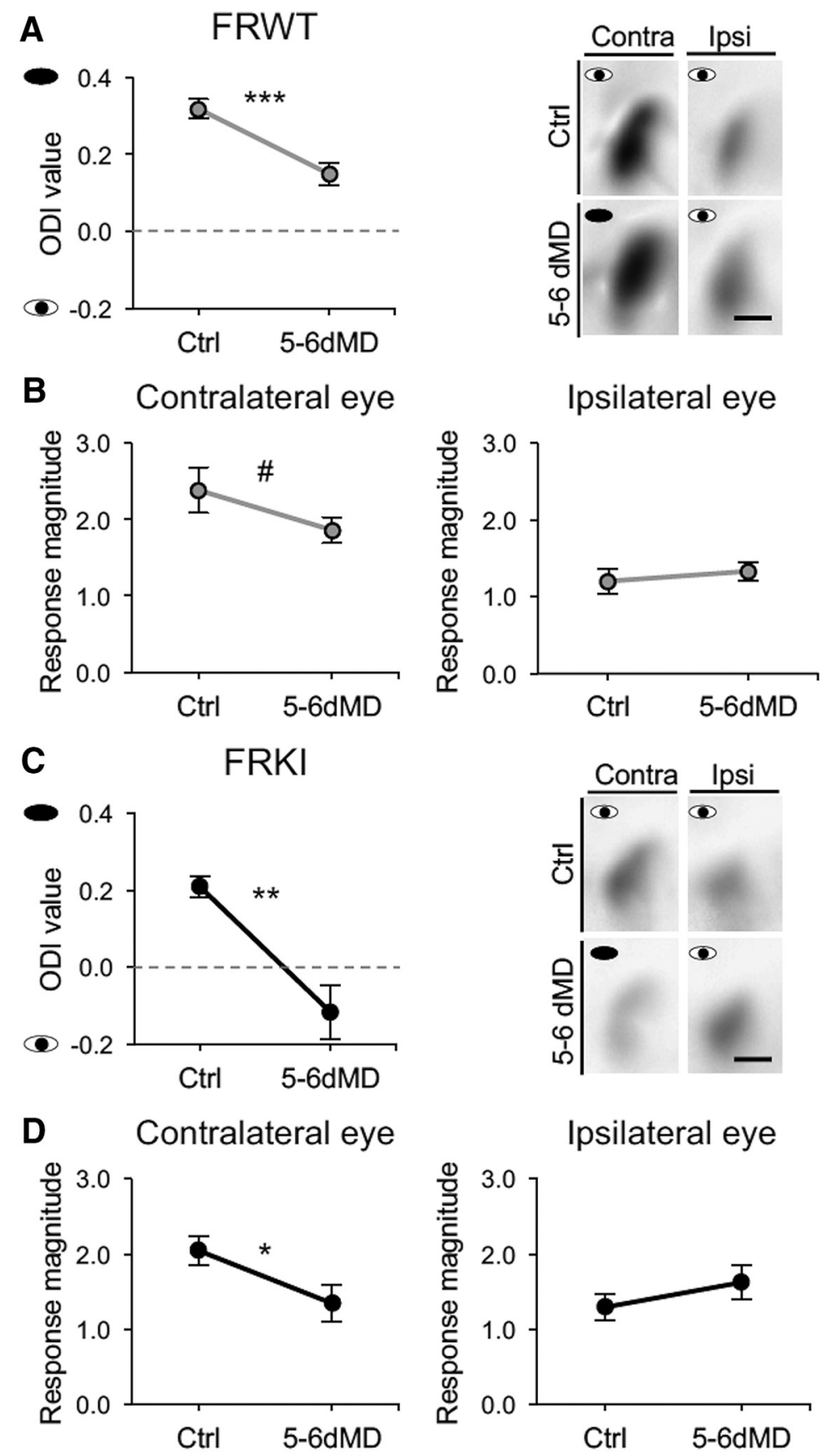

Figure 7. mGluR5-H1a binding is required for establishing normal ODI and sustaining ODI with longer duration MD. Data shown as mean \pm SEM. Response magnitude is of the order $\times 10^{-4} . \mathrm{N}$, Number of animals: FRWT Ctrl,5-6 d MD $=$ 8. FRKI Ctrl,5-6 d MD =6. Statistics, Paired two-tailed Student's $t$ test. $\# p=0.0650{ }^{*} p<0.05,{ }^{* *} p<0.01,{ }^{* *} p<$ $0.001,{ }^{* * *} p<0.0001$. A, Left, Average 0DI measurement from control FRWT and FRWT with 5-6d MD. FRWT Ctrl $=$ $0.32 \pm 0.02$, FRWT $5-6 \mathrm{~d}$ MD $=0.15 \pm 0.03$, paired $t$ test $p=0.0009, t=5.549, \mathrm{df}=7$. Right, Example signals for each eye stimulation for 5-6 d MD and Ctrl groups. Scale Bar, $1 \mathrm{~mm}$. B, Contralateral and ipsilateral raw response magnitude with 5-6 d MD measured in FRWT mice. FRWT Contra: $C$ trl $=2.38 \pm 0.30,5-6 \mathrm{~d} \mathrm{MD}=1.86 \pm 0.17$, paired $t$ test $p=$ $0.0650, t=2.186, \mathrm{df}=7$; FRWT Ipsi: $\mathrm{Ctrl}=1.20 \pm 0.16,5-6 \mathrm{~d} \mathrm{MD}=1.32 \pm 0.12$, paired $t$ test $p=0.1664, t=1.544$, $\mathrm{df}=7$. C, Left, Average ODI data measure in FRKI with 5-6 d MD. FRKI Ctrl $=0.21 \pm 0.03$, FRKI $5-6 \mathrm{~d}$ MD $=-0.12 \pm$ 0.07 , paired $t$ test, $p=0.0061, t=4.550, \mathrm{df}=5$. Right, Example signals for each eye stimulation for corresponding $5-6$ $\mathrm{d}$ MD and Ctrl groups. Scale bar, $1 \mathrm{~mm}$. D, Contralateral and ipsilateral raw response magnitude with 5- $6 \mathrm{~d}$ MD in FRKI mice. FRKI Contra: $C$ trl $=2.04 \pm 0.19,5-6 \mathrm{~d}$ MD $=1.34 \pm 0.24$, paired $t$ test, $p=0.0275, t=3.078, \mathrm{df}=5 ; \mathrm{FRKI}$ Ipsi: $\mathrm{Ctrl}=$ $1.29 \pm 0.18,5-6 \mathrm{~d}$ MD $=1.62 \pm 0.23$, paired $t$ test, $p=0.1422, t=1.741, \mathrm{df}=5$. 
input-specific plasticity may be determined by the nature of neural activity received via distinct inputs.

\section{References}

Antonini A, Stryker MP (1993) Development of individual geniculocortical arbors in cat striate cortex and effects of binocular impulse blockade. J Neurosci 13:3549-3573.

Beattie EC, Stellwagen D, Morishita W, Bresnahan JC, Ha BK, Von Zastrow M, Beattie MS, Malenka RC (2002) Control of synaptic strength by glial TNF $\alpha$. Science 295:2282-2285.

Brakeman PR, Lanahan AA, O’Brien R, Roche K, Barnes CA, Huganir RL, Worley PF (1997) Homer: a protein that selectively binds metabotropic glutamate receptors. Nature 386:284-288.

Cang J, Kalatsky VA, Löwel S, Stryker MP (2005) Optical imaging of the intrinsic signal as a measure of cortical plasticity in the mouse. Vis Neurosci 22:685-691.

Chen WS, Bear MF (2007) Activity-dependent regulation of NR2B translation contributes to metaplasticity in mouse visual cortex. Neuropharmacology 52:200-214.

Chiu C, Weliky M (2001) Spontaneous activity in developing ferret visual cortex in vivo. J Neurosci 21:8906-8914.

Cho KK, Khibnik L, Philpot BD, Bear MF (2009) The ratio of NR2A/B NMDA receptor subunits determines the qualities of ocular dominance plasticity in visual cortex. Proc Natl Acad Sci U S A 106:5377-5382.

Cooke SF, Bear MF (2014) How the mechanisms of long-term synaptic potentiation and depression serve experience-dependent plasticity in primary visual cortex. Philos Trans R Soc Lond B Biol Sci 369:20130284.

Crair MC, Gillespie DC, Stryker MP (1998) The role of visual experience in the development of columns in cat visual cortex. Science 279:566-570.

Crowley JC, Katz LC (2000) Early development of ocular dominance columns. Science 290:1321-1324.

Crozier RA, Wang Y, Liu C-, Bear MF (2007) Deprivation-induced synaptic depression by distinct mechanisms in different layers of mouse visual cortex. Proc Natl Acad Sci U S A 104:1383-1388.

Dudek SM, Bear MF (1992) Homosynaptic long-term depression in area CA1 of hippocampus and effects of $N$-methyl-D-aspartate receptor blockade. Proc Natl Acad Sci U S A 89:4363-4367.

Espinosa JS, Stryker MP (2012) Development and plasticity of the primary visual cortex. Neuron 75:230-249.

Frenkel MY, Bear MF (2004) How monocular deprivation shifts ocular dominance in visual cortex of young mice. Neuron 44:917-923.

Gordon JA, Stryker MP (1996) Experience-dependent plasticity of binocular responses in the primary visual cortex of the mouse. J Neurosci 16:3274-3286.

Heynen AJ, Yoon BJ, Liu CH, Chung HJ, Huganir RL, Bear MF (2003) Molecular mechanism for loss of visual cortical responsiveness following brief monocular deprivation. Nat Neurosci 6:854-862.

Horton JC, Hocking DR (1996) An adult-like pattern of ocular dominance columns in striate cortex of newborn monkeys prior to visual experience. J Neurosci 16:1791-1807.

Hu JH, Park JM, Park S, Xiao B, Dehoff MH, Kim S, Hayashi T, Schwarz MK, Huganir RL, Seeburg PH, Linden DJ, Worley PF (2010) Homeostatic scaling requires group I mGluR activation mediated by Homer la. Neuron 68:1128-1142.

Hubel DH, Wiesel TN (1963) Receptive fields of cells in striate cortex of very young, visually inexperienced kittens. J Neurophysiol 26:994-1002.
Kalatsky VA, Stryker MP (2003) New paradigm for optical imaging temporally encoded maps of intrinsic signal. Neuron 38:529-545.

Kaneko M, Stellwagen D, Malenka RC, Stryker MP (2008) Tumor necrosis factor-alpha mediates one component of competitive, experiencedependent plasticity in developing visual cortex. Neuron 58:673-680.

Kanold PO, Luhmann HJ (2010) The subplate and early cortical circuits. Annu Rev Neurosci 33:23-48.

Kirkwood A, Dudek SM, Gold JT, Aizenman CD, Bear MF (1993) Common forms of synaptic plasticity in the hippocampus and neocortex in vitro. Science 260:1518-1521.

Li Y, Van Hooser SD, Mazurek M, White LE, Fitzpatrick D (2008) Experience with moving visual stimuli drives the early development of cortical direction selectivity. Nature 456:952-956.

Mrsic-Flogel TD, Hofer SB, Ohki K, Reid RC, Bonhoeffer T, Hübener M (2007) Homeostatic regulation of eye-specific responses in visual cortex during ocular dominance plasticity. Neuron 54:961-972.

O'Leary DD, Chou SJ, Sahara S (2007) Area patterning of the mammalian cortex. Neuron 56:252-269.

Park JM, Hu JH, Milshteyn A, Zhang PW, Moore CG, Park S, Datko MC, Domingo RD, Reyes CM, Wang XJ, Etzkorn FA, Xiao B, Szumlinski KK, Kern D, Linden DJ, Worley PF (2013) A prolyl-isomerase mediates dopamine-dependent plasticity and cocaine motor sensitization. Cell 154:637-650.

Phifer CB, Terry LM (1986) Use of hypothermia for general anesthesia in preweanling rodents. Physiol Behav 38:887-890.

Pribiag H, Stellwagen D (2014) Neuroimmune regulation of homeostatic synaptic plasticity. Neuropharmacology 78:13-22.

Rakic P (1976) Prenatal genesis of connections subserving ocular dominance in the rhesus monkey. Nature 261:467-471.

Ranson A, Cheetham CE, Fox K, Sengpiel F (2012) Homeostatic plasticity mechanisms are required for juvenile, but not adult, ocular dominance plasticity. Proc Natl Acad Sci U S A 109:1311-1316.

Rittenhouse CD, Shouval HZ, Paradiso MA, Bear MF (1999) Monocular deprivation induces homosynaptic long-term depression in visual cortex. Nature 397:347-350.

Rochefort NL, Narushima M, Grienberger C, Marandi N, Hill DN, Konnerth A (2011) Development of direction selectivity in mouse cortical neurons. Neuron 71:425-432.

Sato M, Stryker MP (2008) Distinctive features of adult ocular dominance plasticity. J Neurosci 28:10278-10286.

Sawtell NB, Frenkel MY, Philpot BD, Nakazawa K, Tonegawa S, Bear MF (2003) NMDA receptor-dependent ocular dominance plasticity in adult visual cortex. Neuron 38:977-985.

Smith SL, Trachtenberg JT (2007) Experience-dependent binocular competition in the visual cortex begins at eye opening. Nat Neurosci 10:370-375.

Steinmetz CC, Turrigiano GG (2010) Tumor necrosis factor-signaling maintains the ability of cortical synapses to express synaptic scaling. J Neurosci 30:14685-14690.

Stryker MP, Harris WA (1986) Binocular impulse blockade prevents the formation of ocular dominance columns in cat visual cortex. J Neurosci 6:2117-2133.

Weliky M, Katz LC (1999) Correlational structure of spontaneous neuronal activity in the developing lateral geniculate nucleus in vivo. Science 285:599-604.

Wiesel TN, Hubel DH (1974) Ordered arrangement of orientation columns in monkeys lacking visual experience. J Comp Neurol 158:307-318. 